\title{
6 | 2019
}

50. Jahrgang

20. Dezember 2019

S. 473-564

PVSt 7759

Archiv für Presserecht

\section{Zeitschrift für das gesamte Medienrecht}

afp-medienrecht.de Prof. Dr. Karl-Eberhard Hain · Dr. Verena Hoene · Gernot Lehr · Dr. Christian Löffler · Prof. Dr. Roger Mann · Prof. Dr. Karl-Nikolaus Peifer · Dr. Jörg Soehring · Prof. Dr. Christian von Coelln · Vera von Pentz $\cdot$ Georg Wallraf $\cdot$ Prof. Dr. Johannes Weberling

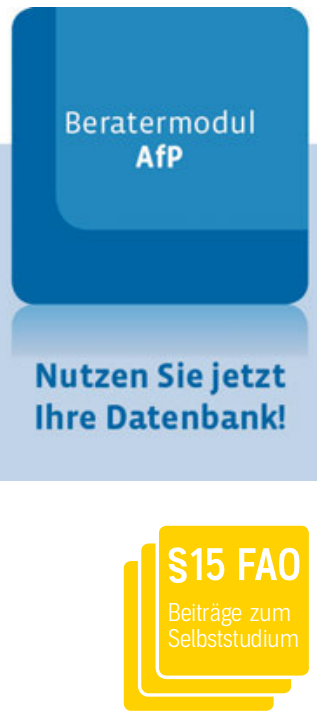

Aufsätze > Martin Nettesheim - Datenschutz und Meinungsäußerungsfreiheit -

Zur Reichweite der Freistellung allgemeiner Meinungsäußerungen

nach Art. 85 Abs. 1 DSGVO

Florian Jotzo - Urheberrechtliche Grenzen der Online-

berichterstattung

Stefan Michel - Reformbedarf des datenschutzrechtlichen

Medienprivilegs für Bloggerinnen?

Max-Julian Wiedemann - Gegendarstellungen gegen Fragen

Entscheidungen $>\quad$ Notifizierungspflicht für Regelung zu Pressesnippets (EuGH, Urt. v.

12.9.2019 - C-299/17)

Unzureichend begründete Medienverfügung (BVerfG, Beschl. v.

21.10.2019 - 1 BvR 2309/19)

Entkräftung der Vermutung der Wiederholungsgefahr durch

anderweitig abgegebene Unterlassungsverpflichtungserklärung

(BGH, Urt. v. 4.6.2019 - VI ZR 440/18)

Rechtswidrigkeit verdeckter Filmaufnahmen in psychiatrischer

Klinik (OLG Köln, Beschl. v. 18.7.2019 - 15 W 21/19) m. Anm. Werner

Bienwald

Unzulässiges kommunales Internetangebot - dortmund.de

(LG Dortmund, Urt. v. 8.11.2019 - 30 262/17)

Keine Formalbeleidigung durch Kommentare mit Sachbezug zu

Facebook-Post (LG Berlin, Beschl. v. 9.9.2019 - 27 AR 17/19) 
